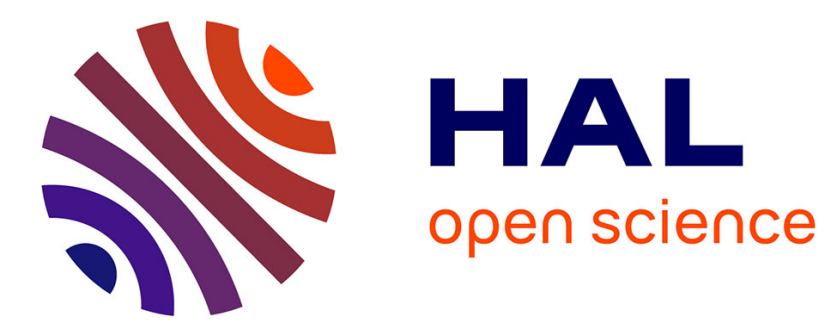

\title{
Introduction of disulfide bridges within silica nanoparticles to control their intra-cellular degradation
}

Sandrine Quignard, Sylvie Masse, Guillaume Laurent, Thibaud Coradin

\section{To cite this version:}

Sandrine Quignard, Sylvie Masse, Guillaume Laurent, Thibaud Coradin. Introduction of disulfide bridges within silica nanoparticles to control their intra-cellular degradation. Chemical Communications, 2013, 49 (33), pp.3410-3412. 10.1039/c3cc41062e . hal-01461411

\section{HAL Id: hal-01461411 \\ https://hal.science/hal-01461411}

Submitted on 27 Sep 2018

HAL is a multi-disciplinary open access archive for the deposit and dissemination of scientific research documents, whether they are published or not. The documents may come from teaching and research institutions in France or abroad, or from public or private research centers.
L'archive ouverte pluridisciplinaire HAL, est destinée au dépôt et à la diffusion de documents scientifiques de niveau recherche, publiés ou non, émanant des établissements d'enseignement et de recherche français ou étrangers, des laboratoires publics ou privés. 


\title{
Introduction of disulfide bridges within silica nanoparticles to control their intra-cellular degradation
}

\author{
Sandrine Quignard, Sylvie Masse, Guillaume Laurent, and Thibaud Coradin*
}

\begin{abstract}
Incorporation of disulfide bridges in the core structure of silica nanoparticles modifies their intracellular fate within dermal fibroblasts, especially influencing their degradation pathway.
\end{abstract}

The intracellular delivery of bioactive molecules using colloidal carriers is a challenging area where the successive steps of internalization, cellular trafficking, drug release and externalization must be finely controlled. ${ }^{1}$ The first two steps are intimately related as a suitable surface modification allows the selection of the internalization pathway that will also impact on their intracellular fate. ${ }^{2}$ It is then possible to introduce specific functionalities within the carrier to take advantage of cellular strategies for degradation, mainly acidification and reduction via an enzymatic process. ${ }^{3}$ In this context, introduction of disulfide S$S$ bonds either within the particle backbone or as a link between the drug and its surface/porosity has been largely studied. ${ }^{4,5}$ Noticeably, in the case of silica nanoparticles, only the second strategy has been largely explored so far. ${ }^{6}$ One recent example also described the silicification of disulfide-incorporating polymer nanoparticles. ${ }^{7}$

We have recently demonstrated the intracellular degradation of plain silica nanoparticles and could demonstrate the excretion of the products of this process, both in a soluble and particulate form. ${ }^{8}$ This degradation was attributed to the intrinsic solubility of silica in water, whose dissolution was favored by the continuous externalization of solubilization products. As a mean to gain some control on this process, we have explored the possibility to introduce disulfide bonds within the silica backbone and studied the intracellular fate of these hybrid nanoparticles in human dermal fibroblasts.

The preparation of the disulfide-containing silica particles ( $x \% S S)$ was based on the Stöber process $^{9}$ involving tetraethoxysilane (TEOS)/ammonia/ethanol mixtures by additional introduction of an increasing amount ( $x$ in wt\%) of bis(triethoxysilyl-propyl)disulfide (BTSPD) (ESI-1). Based on our previous results, the size of the sulfide-free particles was selected to be $c a .40 \mathrm{~nm}$ as they are uptaken rapidly without inducing significant cytotoxic effect. The covalent grafting of the fluorescein isothiocyananate (FITC) within the particle core via the incorporation of aminopropyltriethoxysilane (APTES) was also performed, allowing their intracellular visualization. ${ }^{10}$

The incorporation of S-S bridges was first checked by elemental analysis, indicating that the S:Si ratio increases with BTSPD content but also that its incorporation to the silica particle was not complete (Table 1). The size of the particles was not significantly modified by the presence of BTSPD (ESI-2). In the culture medium, the zeta-potential $\zeta$ values were positive, due to the presence of the amino groups of APTES on the particle surface, and slightly increase with SS content, suggesting a limited influence of BTSPD incorporation on the surface composition. Noticeably, attempts to incorporate more BTSPD were unsuccessful, leading to inhomogeneous products.

Table 1. Elemental composition (in wt\%), diameter $D$ (in $\mathrm{nm}$ ) and zeta potential $\zeta$ (in $\mathrm{mV}$ ) of silica particles

$\begin{array}{ccccccc} & \mathrm{S}(\%) & \mathrm{Si}(\%) & \mathrm{C}(\%) & \mathrm{N}(\%) & D^{\mathrm{a}}(\mathrm{nm}) & \zeta^{\mathrm{b}}(\mathrm{mV}) \\ 0 \% \mathrm{SS} & - & 38.8 & 2.4 & 0.55 & 38 & +8 \\ 10 \% \text { SS } & 2.6 & 37.4 & 4.8 & 0.40 & 44 & +5 \\ 20 \% \text { SS } & 3.5 & 36.4 & 8.0 & 0.45 & 45 & +4 \\ 30 \% \text { SS } & 4.8 & 35.4 & 9.3 & 0.45 & 48 & +13 \\ 40 \% \mathrm{SS} & 6.5 & 33.9 & 11.5 & 0.45 & 46 & +13\end{array}$

$\mathrm{a} \pm 7 \mathrm{~nm}$, from TEM; ${ }^{\mathrm{b}} \pm 3 \mathrm{mV}$, in culture medium

The internal structure of the particles was studied by solid state Nuclear Magnetic Resonance (ssNMR). As shown in Figure 1a, the cross-polarization (CP) $\left\{{ }^{1} \mathrm{H}\right\}-{ }^{13} \mathrm{C}$ spectrum of the initial silica particles (0\%SS) consisted of the APTES propyl chain resonances at 9.3, 21.3 and $42.7 \mathrm{ppm}$, together with ethoxy groups at 17.6 ppm and $58.9 \mathrm{ppm}$ corresponding to non-hydrolysed TEOS or APTES. By introducing an increasing amount of BTSPD, its propyl chain peaks would overlap with APTES at 11.8, 23.1 and $41.8 \mathrm{ppm}$. Noticeably no new peak was observed at $29.1 \mathrm{ppm}$ that would have indicated disulfide reduction into thiol during the synthetic process. Starting from $20 \%$ SS, the intensity of the ethoxy group signals strongly increased with BTSPD content, which was also confirmed by the quantitative ${ }^{1} \mathrm{H}$ ssNMR spectra (not shown), indicating decreasing hydrolysis rate. Moreover, a novel environment of ethoxy groups was detected at $18.8 \mathrm{ppm}$, suggesting that some segregation may have occurred.

Figure $1 \mathrm{~b}$ shows the $\left\{{ }^{1} \mathrm{H}\right\}-{ }^{29} \mathrm{Si} C P$ ssNMR spectra of the $x \% S S$ particles. As expected, the proportion of $\mathrm{T}^{n}$ species (i.e. with one $\mathrm{Si}-\mathrm{C}$ bond and $n$ Si-O-Si [-40 ppm to $-70 \mathrm{ppm}]$ ) relative to $\mathrm{Q}^{n}$ species (i.e. with four $\mathrm{Si}-\mathrm{O}$ bonds [-90 ppm to $-120 \mathrm{ppm}]$ ) is correlated to the BTSPD amount, confirming its incorporation into the silica matrix. A peak of increasing intensity was also noticed at $-46.4 \mathrm{ppm}$. In agreement with the ${ }^{29} \mathrm{Si}$ liquid state NMR spectra of partially hydrolysed BTSPD (Fig 1f), this 

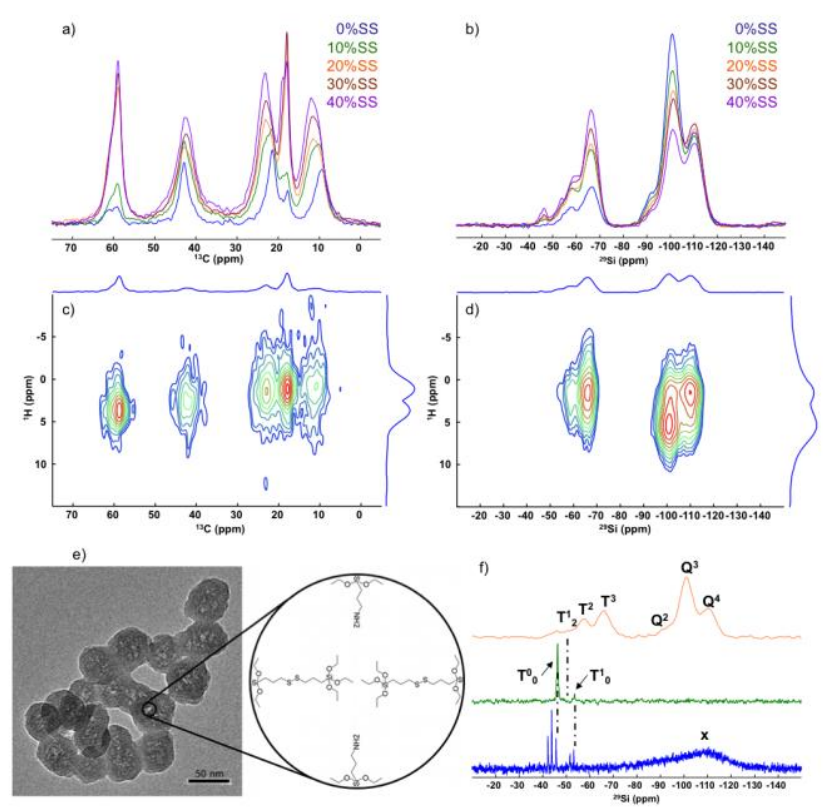

Fig. 1. (a) $\left\{{ }^{1} \mathrm{H}\right\}{ }^{-13} \mathrm{C} C P$ and $(\mathrm{b})\left\{{ }^{1} \mathrm{H}\right\}-{ }^{29} \mathrm{Si} C P$ ssNMR spectra of $x \% \mathrm{SS}$ particles; (c) $\left\{{ }^{1} \mathrm{H}\right\}-{ }^{13} \mathrm{C}$ and (d) $\left\{{ }^{1} \mathrm{H}\right\}{ }^{-29} \mathrm{Si}$ HETCOR ssNMR spectra of $30 \% \mathrm{SS}$, (e) TEM and schematic structure of $30 \% \mathrm{SS}$, (f) $\left\{{ }^{1} \mathrm{H}\right\}{ }^{-29} \mathrm{Si} \mathrm{CP}$ (red line) and $\left\{{ }^{1} \mathrm{H}\right\}{ }^{29} \mathrm{Si}$ INEPT (green line) ssNMR spectra of APTES-free $30 \% \mathrm{SS}$, liquid state NMR ${ }^{29} \mathrm{Si}$ of partially-hydrolysed BTSPD.

resonance was attributed to $\mathrm{T}_{0}^{0}$ species, i.e. $\mathrm{C}-\mathrm{Si}(\mathrm{OEt})_{3}$ groups that are neither hydrolyzed nor forming Si-O-Si bonds. ${ }^{11}$ Since long $\left\{{ }^{1} \mathrm{H}\right\}{ }^{29} \mathrm{Si} \mathrm{CP}$ contact time experiments (not shown) suggested a high mobility for these species, we applied a refocalized $\left\{{ }^{1} \mathrm{H}\right\}-{ }^{29} \mathrm{Si}$ INEPT sequence (Insensitive Nuclei Enhanced by Polarization Transfer $)^{12}$ on the APTES-free $30 \%$ SS sample (Fig. 1f). Two resonances were observed at $-46.4 \mathrm{ppm}\left(\mathrm{T}^{0}{ }_{0}\right)$ and at $-53.6 \mathrm{ppm}$ $\left(\mathrm{T}^{1}{ }_{0}\right.$, i.e. $\mathrm{C}-\mathrm{Si}(\mathrm{OSi})(\mathrm{OEt})_{2}$ species), confirming our previous attribution.

2D ssNMR experiments were then undertaken on the $30 \% \mathrm{SS}$ sample to compare the $\left\{{ }^{1} \mathrm{H}\right\}-{ }^{13} \mathrm{C}$ HETCOR (HETeronuclear CORrelation, Fig 1c) and the $\left\{{ }^{1} \mathrm{H}\right\}{ }^{29}$ Si HETCOR spectra (Fig 1d). The same analysis was also performed on the $30 \%$ SS sample without APTES (ESI-3), both indicating a major unexpected correlation between the ethoxy group (mainly in the ${ }^{1} \mathrm{H}$ 1-2 ppm range) and the $Q^{4}$ species $(-110 /-115 \mathrm{ppm})$. Taken together, these data suggest that some non-hydrolyzed end groups of BTSPD are incorporated within the silica structure of the nanoparticles, probably as pending arms anchored by the opposite end group to the silica network (Fig. 1e). Interestingly, Transmission Electron Microscopy showed that the particles had a granular core, which may reflect the existence of internal BTSPD domains (Fig. 1e). Such a pending situation is unlikely to occur at the particle surface due to the expected fast hydrolysis in the presence of external solvent. The presence of APTES domains cannot be fully put aside as $\mathrm{T}^{1}{ }_{0}$ species may correspond to its binding to the silica network via a single Si-O-Si bond.

The influence of S-S incorporation on the dissolution of the particles was first monitored in cell-free media $\left(\left[\mathrm{SiO}_{2}\right]=0.6\right.$ mg.mL ${ }^{-1}-10 \mathrm{mM}$ ). At both $\mathrm{pH} 7.4$ (Tris buffer, ESI-4) and $\mathrm{pH} 4.5$ (acetate buffer, Fig. 2a), the kinetics of silica dissolution and the dissolution rate were followed by titrating silicic acid via the
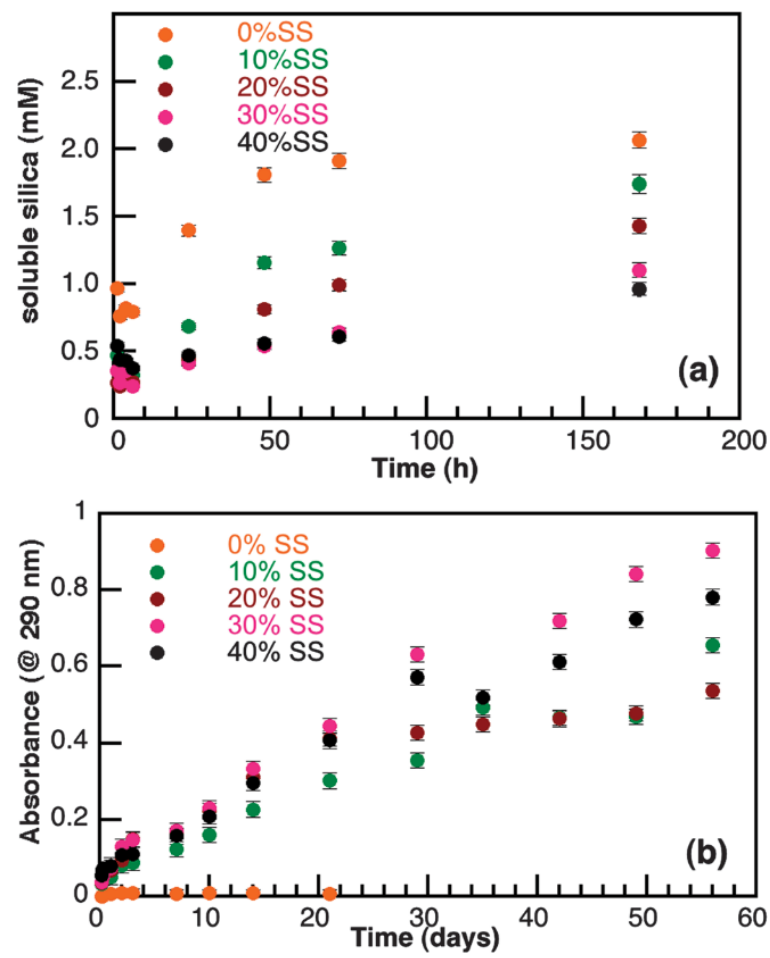

Fig. 2. (a) Silica particles dissolution at $\mathrm{pH} 4.5$; (b) silica particles reduction by DTT at $\mathrm{pH} 7.4$

silicomolybdate method, ${ }^{13}$ showing that they both decrease with increasing amount of incorporated disulfide groups. The reduction of disulfide bonds was studied using DTT (dithiothreitol), a reducing agent usually considered as a model of intracellular enzymes, whose oxidised form exhibits an absorption band at $290 \mathrm{~nm} .{ }^{14}$ The experiment was performed at $\mathrm{pH} 7.4,37^{\circ} \mathrm{C}$ in the absence of oxygen over 2 months. As shown on Fig. $2 b$, the most efficient reduction is observed for the $30 \% \mathrm{SS}$ particles. The $40 \%$ SS exhibited less reactivity, which might be due to a more difficult access of DTT to the particle core. As expected the 0\%SS showed no reduction.

The particle uptake by primary adult dermal fibroblasts (HDFa) in culture medium was followed by fluorescent microscopy using the same silica concentration. ${ }^{7}$ After $24 \mathrm{~h}$, the intracellular localization of silica nanoparticles was evidenced for $0 \%$ SS but not for the SS-containing materials that tend to be attached to the cell outer membrane (ESI-5). In contrast, after 7 days, light blue aggregates, resulting from the combination of FITC green fluorescence and Lysosensor dark blue fluorescence and therefore corresponding to internalized particles, ${ }^{8}$ were observed for all samples, but this effect appeared more pronounced for pure SS and 10\%SS (Fig. 3 and ESI-5). The internalization was confirmed by TEM imaging evidencing the presence of colloidal particles within all cells (Fig. 3 and ESI-6). In addition it was observed that the structure of the SS-containing particles had evolved towards hollow nanospheres, a phenomenon that was not observed for pure silica colloids. This suggests that core dissolution is favoured over surface erosion, reflecting the sensitivity of the disulfide-bridged domains to the intracellular conditions. Similar observations were previously reported for silica-coated gelatin particles after cell internalization as well as for silica-alginate hybrid colloids in vitro and in cell-free 

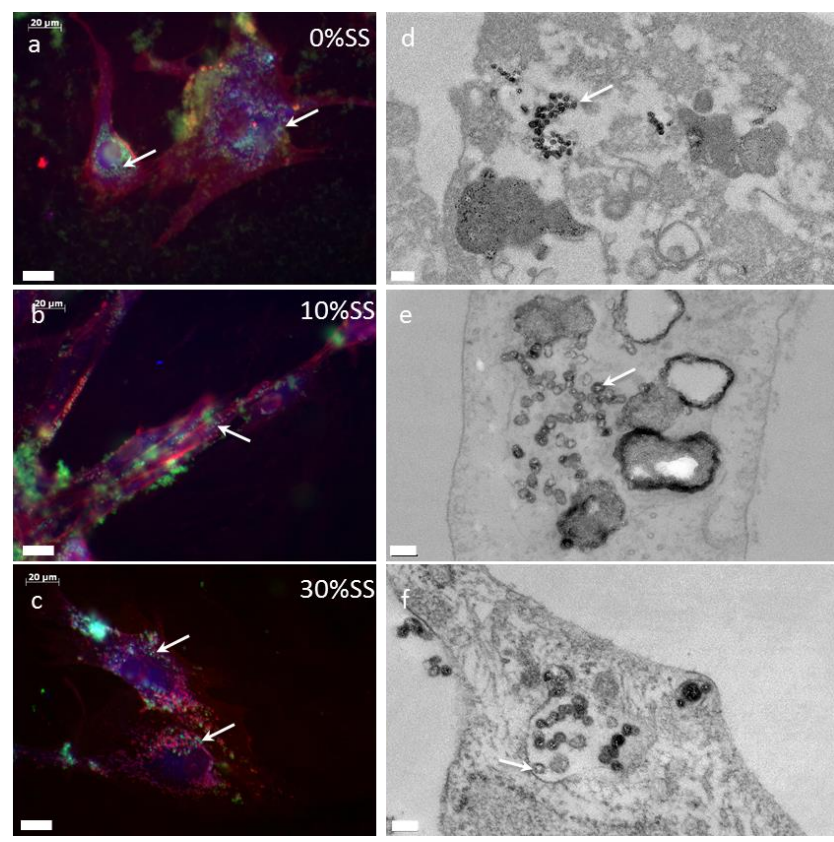

Fig. 3 Internalization of silica nanoparticles after 7 days of contact as studied by (a-c) fluorescence optical microscopy (scale bar $=20 \mu \mathrm{m}$ ) and

(d-f) TEM (scae bar $=100 \mathrm{~nm}$ ). WGA-AlexaFluor555 and Lysosensor

yellow-blue were used for red staining of the membrane and blue staining of the endosomes, respectively. Green fluorescence corresponds to FITC.

solutions. ${ }^{15}$ After 7 days of contact, the cells were rinsed from remaining external particles and left in culture conditions for an additional week.

The hollow structures were more clearly evidenced and some of the particles were also observed outside the cells (ESI-6). In parallel, the analysis of the culture medium was performed by fluorescence after separation of the soluble and particulate components by centrifugation/filtration. Interestingly, for SS-free particles, more nanoparticles are being released than solubilised forms. As the amount of SS increases, the soluble forms become prevalent over the nanoparticles (Fig. 4). In parallel viability tests performed using the Alamar Blue method showed no significant toxicity for any of the particles at the studied concentration (ESI7).

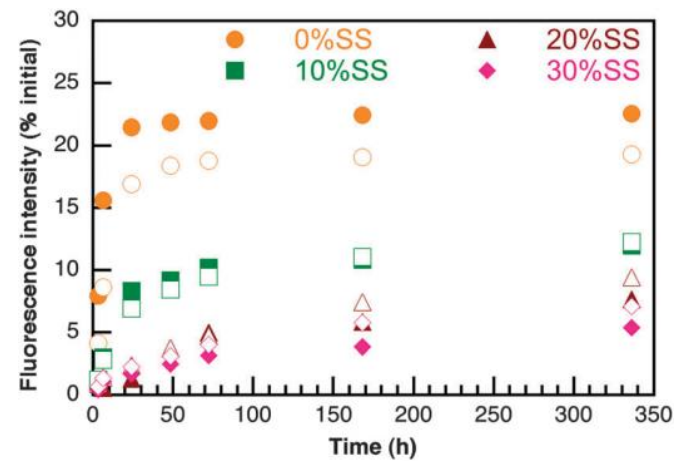

Fig. 4 Silica exocytosis from dermal fibroblasts as monitored by FITC fluorescence of nanoparticles (NPs, filled symbols) and soluble forms (open symbols).

Therefore the incorporation of disulfide bonds in the backbone of silica nanoparticles provides a simple method for controlling their intracellular degradation, both from a kinetic and structural point of view. The next challenge to address is the drug loading efficiency of these hybrid nanomaterials, which is an important limitation for plain silica particles compared to mesoporous carriers, before their application in intracellular delivery can be fully assessed.

\section{Notes and references}

aUPMC Univ Paris 06, UMR 7574, Chimie de la Matière Condensée de Paris, Collège de France, 11 place Marcelin Berthelot, 75231 Paris Cedex 05, France. Fax: +33-144271504; Tel: +33-1-44271528; E-mail: thibaud.coradin@upmc.fr

${ }^{\mathrm{b} C N R S, ~ U M R ~ 7574, ~ C h i m i e ~ d e ~ l a ~ M a t i e ̀ r e ~ C o n d e n s e ́ e ~ d e ~ P a r i s, ~ C o l l e ̀ g e ~ d e ~}$ France, 11 place Marcelin Berthelot, 75231 Paris Cedex 05, France.

'Collège de France, UMR 7574, Chaire des Matériaux hybrides, Collège de France, 11 place Marcelin Berthelot, 75231 Paris Cedex 05, France.

+ Electronic Supplementary Information (ESI) available: Full experimental procedures; TEM images of particles; additional HETCOR SSNR data; particle dissolution at $\mathrm{pH} 7.4$; complete sets of fluorescence and TEM images; cytotoxicity assays. See DOI: 10.1039/b000000x/

1 Intracellular delivery: fundamentals and applications, ed. A. Prokop, Springer, Dordrecht, 2011.

2 H. Hillaireau and P. Couvreur, Cell. Mol. Life Sci., 2009, 66, 2873-2896.

3 (a) G. Saito, J. A. Swanson and K. D. Lee, Adv. Drug Deliv., 2003, 55, 199; (b) K. R. West and S. Otto, Curr. Drug Discovery Technol., 2005, 2, $123-160$.

4 (a) N. W. S. Kam, Z. Liu and H. Dai, J. Am. Chem. Soc. 2005, 127, 1249212493; (b) R. Hong, G. Han, J. M. Fernandez, B. J. Kim, N. S. Forbes and V. M. Rotello, J. Am. Chem. Soc., 2006, 128, 1078-1079; (c) S. Cerritelli, D. Velluto and J. A. Hubbell, Biomacromolecules, 2007, 8, 1966-1972

5 (a) A. N. Koo, H. J. Lee, S. E. Kim, J. H. Chang, C. Park, C. Kim, J. H. Park and S. C. Lee, Chem. Commun., 2008, 6570-72; (b) H.-Y. Wen, H.-Q. Dong, W.-J. Xie, Y.-Y. Li, K. Wang, G. M. Pauletti and D.-L. Shi, Chem. Commun. 2011, 47, 3550-3552; (c) T. Thambi, V. G. Deepagan, H. Ko, D. S. Lee and J. H. Park, J. Mater. Chem., 2012, 22, 22028-22036.

6 (a) C. Y. Lai, B. G. Trewyn, D. M. Jeftinija, K. Jeftinija, S. Xu, S. Jeftinija and V. S. Y. Lin, J. Am. Chem. Soc., 2003, 125, 4451-4459; (b) R. Mortera, J. Vivero-Escoto, I. I. Slowing, E. Garrone, B. Onida and V. S. Y. Lin, Chem. Commun., 2009, 22, 3219-3221; (c) A. M. Sauer, A. Schlossbauer, N. Ruthardt, V. Cauda, T. Bein and C. Bräuchle, Nano Lett., 2010, 10, 3684-3691; (d) Y. Cui, H. Dong, X. Cai, D. Wang and Y. Li, ACS Appl. Mater. Interfaces, 2012, 4, 3177-3183

7 N. Gouda, K. Miyata, R .J. Christie, T. Suma, A. Kishimura, S. Fukushima, T. Nomoto, X. Liu, N. Nishiyama and K. Kataoka, Biomaterials, 2013, 34, 562-570.

8 S. Quignard, G. Mosser, M. Boissière and T. Coradin, Biomaterials, 2012, 33, 4431-4442.

9 W. Stöber, A. Fink A and E. Bohn, J Colloid Interface Sci. 1968, 26, 62 69.

10 A. van Blaaderen and A. Vrij, Langmuir 1992, 8, 2921-2931.

11 S. Prabakar, R. A. Assink, N. K. Raman, S. A. Myers and C.J. Brinker, J. Non Cryst. Solids, 1996, 202, 53-60

12 (a) C. Bonhomme, C. Coelho, N. Baccile, C. Gervais, T. Azaïs and F. Babonneau, Acc. Chem. Res. 2007, 40, 738-746 ; (b) F. Brunet, J. NonCryst. Solids, 1998, 231, 58-77

13 T. Coradin, D. Eglin and J. Livage, Spectroscopy, 2004, 18, 567-576.

14 B. Arunachalam, U. T. Phan, H. J. Gueuze and P. Cresswell, Proc. Natl Acad. Sci., USA, 2000, 97, 745-750.

15 (a) J. Allouche, M. Boissière, C. Hélary, J. Livage and T. Coradin, J. Mater. Chem., 2006, 16, 3121-3126; (b) M. Boissière, P. J. Meadows, R. Brayner, C. Hélary, J. Livage and T. Coradin, J. Mater. Chem., 2006, 16, 1178-1182; (c) Y. Yang and T. Coradin, Green Chem. 2008, 10, 183190. 